the south, with the northern population remaining safe for at least another five years.

Scientists are concerned that the plans could herald the end of an internationally valuable long-term population study, and hope that $\mathrm{SNH}$ will consider leaving the northern-block population alone.

"The long-term red-deer study has profoundly influenced our understanding of important conceptual issues in evolutionary biology - for example, sexual selection and sex allocation and population biology, including factors such as density dependence and the maintenance of genetic variation," says Andrew Cockburn, a behavioural ecologist at the Australian National University in Canberra, who is familiar with the studies.

"The research also has had great consequences for our understanding of the management of ungulate populations. Perhaps most important, the study has clearly not run its course, as fascinating recent results on sex ratios attest. It would be very disappointing to see the work come to an end."

Josephine Pemberton, a population biologist at the University of Edinburgh is one of the authors of a recent paper on sex ratios in Rum red deer (see Nature $399,459 ; 1999)$. She says the deer, which are individually monitored, "should be seen as a national and international resource for research and education which has its own intrinsic value".

Usher acknowledges the researchers' concerns. But he argues that they should now be addressing the substantial opportunities for researching how a deer population at normal density would change in a more diverse landscape.

Another scientist suggests that Rum could be treated as a demonstration case for other areas of Scotland where similar replanting is occurring next to high-density deer populations. "You would have to accept high-density populations of deer in areas adjacent to where conservationists want to plant," says Steve Albon, from the Institute of Terrestrial Ecology in Banchory, Scotland.

Although SNH says it is committed to the concept of Rum as an outdoor laboratory, it wants to limit future research. A spokesperson said "we do have a difficulty with current research work, which is conflicting with the management of the reserve". SNH's vision includes increasing visitor numbers to the island and, in the long term, allowing more people to live there.

\title{
Young, worldly and unhelpful all miss out on data sharing
}

\section{Washington}

Researchers who refuse to share data may provoke others to withhold results from them, according to a study by health-policy analysts at Harvard Medical School.

The study found that young researchers, those who publish a lot, and investigators seeking patents are most likely to be denied access to biomedical data and reagents. It also found that researchers who withhold data gain a reputation for this and have more difficulty in obtaining data from others.

The study, whose results are published in the February issue of Research Policy, was conducted by a research team led by sociologist Eric Campbell at Harvard Medical School's Institute of Health Policy.

The team surveyed 2,366 randomly selected scientists - both clinical and nonclinical — at 117 US medical schools. Overall, 12.5 per cent said they had been denied access to other academic investigators' data, excluding article reprints, during the past three years. This corresponds with previous findings by the team and other groups.

But, by examining the 'victims' of data withholding, the team identified those experiencing the most difficulty. For junior staff members, the team found that 13.5 per cent were denied access, compared with 5.1 per cent of senior researchers.

The relationship between data withholding and researchers' publishing records during the preceding three years was striking: 7.7 per cent of those who had published 1-5 articles had had data withheld from them, but this rose to 28.9 per cent for researchers who had published more than 20

Among those who had applied for a patent, 30 per cent had been refused access to data, compared with 9.4 per cent of those

Researchers denied access to data over the past three years

Researcher Percentage of requests denied

\begin{tabular}{ll} 
Has MD & 9.2 \\
\hdashline & 1
\end{tabular}

No MD 17.7

Publishing record:

$1-5$ articles $\quad 7.7$

$>20$ articles $\quad 28.9$

Applied for patent?

Yes $\quad 30$

No 9.4

Member of federal review board/study panel?

Yes $\quad 20.2$

No 1.6

who had not applied for a patent. Scientists who reported refusing to share data were more than twice as likely to be the victims of data withholding as those who had not.

"Selectively withholding research results from the most productive and commercially active researchers could slow the progress towards understanding the causes and cures of human disease," warns Campbell.

The National Institutes of Health issued guidelines last year encouraging the sharing of materials and data, but some scientists say these need tightening. Campbell and his colleagues make several recommendations to institutions regarding data sharing. For example, they suggest that senior staff should be encouraged to help junior scientists gain access to results and materials from other researchers and that professional societies and funding agencies should encourage data sharing.

"We welcome the study," said Jonathan Knight, associate secretary of the American Association of University Professors. "The study shows some concrete dimensions to the problem."

Rex Dalton

\section{US eases Israelis' lab access}

\section{Jerusalem}

Israeli scientists will have an easier time visiting and working with laboratories run by the US Department of Energy under an agreement signed last week.

Under the terms of the agreement, signed by US Secretary of Energy Bill Richardson and Israel's Minister of National Infrastructure, Eli Suissa, Israeli scientists will no longer have to undergo thorough and lengthy security clearances before being allowed to visit the laboratories.

These clearances were imposed on Israeli scientists in the wake of the conviction of
Jonathan Pollard, an American who spied for Israel, in 1986. They were tightened up in 1998 following of the arrest of Wen Ho Lee, a Los Alamos scientist who is suspected of spying for China.

At their meeting last week, Richardson and Israeli officials also discussed cooperation on technical means of monitoring the Nuclear Non-proliferation Treaty.

Israel has declined to sign the treaty and has maintained a deliberate silence about its nuclear weapons programme. However, the country is widely believed to have built up a nuclear arsenal.
Haim Watzman 